\title{
Installation Effects of a Propeller Mounted on a High-Lift Wing with a Coanda Flap. Part I: Aeroacoustic Experiments
}

\author{
R.A.D. Akkermans, M. Pott-Pollenske† H. Buchholz; J.W. Delfs \\ Institute of Aerodynamics and Flow Technology, Dept. of Technical Acoustics \\ German Aerospace Center (DLR), Lilienthalplatz 7, 38108 Braunschweig, Germany
}

\begin{abstract}
In this contribution, we present aeroacoustic experiments concerning installation effects of propellers. Such installation effects are important as they can significantly alter the sound radiation as compared to an isolated propeller. For this purpose, detailed experiments have been conducted in the NWB aeroacoustic wind tunnel in Braunschweig, Germany. The considered geometry is a nine-bladed propeller installed in front of a high-lift wing (employing a Coanda flap). The results illustrate the influence of propeller rotational speed, blade pitch angle, wind tunnel velocity, and angle of attack variations on the sound radiation. Furthermore, with a source localisation technique insight is gained in the dominant sound sources, and reveals the importance of periodic as well as broadband noise for the considered geometry.
\end{abstract}

\section{Introduction}

The German collaborative research project "Bürgernahes Flugzeug" (English: Metropolitan Aircraft) pursues the vision to substantially integrate small regional airports within the European aviation network. To facilitate such an integration, a medium-sized airplane with short take-off capabilities is needed. Due to several factors (i.e., range, speed, passenger capacity, and runway length) a combination of a high-lift wing (employing a Coanda flap) and a propeller as propulsion system is chosen. One of the challenges is a solution of the potential conflict between growth of the air transport system on the one hand, and the required reduction of the noise impact on the other hand.

The sound radiation of an isolated propeller is well understood, starting from the work by Gutin in 1936. ${ }^{1}$ However, the installation of a propulsion system on an aircraft breaks the "isolation", i.e., results in a distortion of the propeller inflow due to the upstream flow effect of the wing in a tractor configuration or the impingement of the pylon wake on the rotor in a pusher propeller configuration.

Two kinds of installation effects are distinguished, i.e., aerodynamic and aeroacoustic installation effects. Aerodynamic installation refers to effects that the flow field produced by the pylon, wing, or fuselage results in the propeller operating in a non-uniform flow field (a source effect). Aeroacoustic installation denotes the effects resulting from the sound field produced by the propeller propagating through a non-uniform flow field, due to the possible presence of a wing, pylon, or fuselage. This latter effect, contrary to the source effect of aerodynamic installation, is solely a propagation effect.

In the past, a mutual increase in propulsion efficiency and a decrease in noise radiation was achieved by increasing the by-pass ratio of the engine. A design based on a single component becomes more and more rudimentary as the increased by-pass ratio results in a stronger coupling between the individual components, due to the increased geometrical closeness of engine and for instance the wing (e.g., the jet-flap interaction of

\footnotetext{
${ }^{*}$ Research scientist, Dept. of Technical Acoustics, AIAA Member.

$\dagger$ Research scientist, Dept. of Technical Acoustics, senior AIAA Member.

${ }^{\ddagger}$ Research engineer, Dept. of Technical Acoustics, AIAA Member.

$\S$ Professor \& Department head, Dept. of Technical Acoustics, senior AIAA Member.

ฯ Research engineer, Dept. of Technical Acoustics, AIAA Member.
} 
an ultra-high by-pass ratio fan closely mounted underneath a wing). On the other hand, installation effects can be used beneficial by geometrically shielding certain radiation directions from the noise source (e.g., partially buried engine intakes or overwing mounted engines).

To be able to account for all of the complex installation effects at a complete aircraft during the design phase a fast but sufficiently reliable noise prediction method is needed. For this reason, the aeroacoustic influence of the engine is modeled and directly coupled into the CAA simulations. Within the BNF project, we focus on the complex installation effect of a propeller mounted in front of a wing equipped with a Coanda flap to produce a high lift. The modeling enables a fast computation of the installation effects, both aerodynamic as well as aeroacoustic, while correctly taking into account the non-uniform (background) flow field. This modeling and simulation approach have to be validated by experiments and these high-quality experiments are the subject of this contribution. See Dierke et al. ${ }^{2}$ for the numerical simulation approach and its experimental validation.

In this contribution, we present an experimental aeroacoustic investigation of propeller installation effects where the propeller was mounted in front of a high-lift wing. The experiments have been conducted in the aeroacoustic/aerodynamic wind tunnel NWB at DLR Braunschweig. The influence of several factors on the far field sound radiation has been investigated, such as wind tunnel velocity, angle of attack, blade pitch angle, and rotational speed of the propeller. The aerodynamic operating condition was verified (i.e., attached flow on the Coanda flap and angle of attack within linear regime of the lift curve). Furthermore, spectral results around the propeller plane show the influence when changing the loading noise contribution with respect to the thickness noise. The sound radiation seems to be fairly insensitive to wind tunnel speed and geometrical angle of attack, at least for the considered operating conditions. Source distribution plots give insight into the possible importance of different source mechanisms.

This proceeding is organized as follows: in Section II an short overview of propeller sound is given, as well as aeroacoustic experiments hereof. The experimental model, aeroacoustic wind tunnel, measurement technique, and test matrix are described in the third Section. Hereafter, results of the aerodynamic operating condition is discussed and results regarding the aeroacoustic experiments are presented with emphasis on FF spectra. Source localisation results obtained with the microphone array technique are also presented in Section 4. Finally, in Sect. V the conclusions are summarized.

\section{Propeller Sound}

The here presented overview on propeller sound is divided in to the sound field cause by an isolated propeller, installed propeller, and aeroacoustic experiments concerning propeller noise. The first two subsections, on isolated and installed propeller sound field, follow Ref. ${ }^{3}$ closely.

\section{A. Sound field of an isolated propeller}

The sound generated by a propeller rotating with a speed $N_{P}$, having a radius $R$, with flow Mach number $M_{\infty}$ is determined by the helical blade-tip Mach number $M_{H}=\sqrt{M_{\infty}^{2}+M_{\Omega}^{2}}$. Here, $M_{\Omega}$ denotes the circumferential Mach number (or tip Mach number) defined as $\Omega R / a_{\infty}$. Typically, propeller driven airplanes operate in subsonic flow Mach numbers, i.e., $M_{H}<1$. For such conditions, the sound generated by a propeller consists of a combination of thickness, loading, and quadrupole noise. This can be illustrated with the Ffowcs-Williams \& Hawkings equation. ${ }^{4}$ In the so-called solid formulation (using as acoustic variable the density fluctuations $\rho^{\prime}$ ), the Ffowcs-Williams \& Hawkings equation reads

$$
4 \pi a_{\infty}^{2} \rho^{\prime}(\boldsymbol{x}, t)=\underbrace{\nabla_{x} \cdot \nabla_{x} \cdot \int_{V_{H}^{+}} \frac{\boldsymbol{T}}{r\left|1-M_{r}\right|} d V(\eta)}_{\text {quadrupole noise }}+\underbrace{\nabla_{x} \cdot \int_{\partial V_{H}} \frac{(p \boldsymbol{I}-\boldsymbol{\tau}) \boldsymbol{n}}{r\left|1-M_{r}\right|} d S(\eta)}_{\text {loading noise }}+\underbrace{\frac{\partial}{\partial t} \int_{\partial V_{H}} \frac{\rho_{\infty} v_{n}}{r\left|1-M_{r}\right|} d S(\eta)}_{\text {thickness noise }} .
$$

In this equation, $a_{\infty}$ is the speed of sound, $r$ is the distance between source position $\eta$ and observer position $x$. The relative Mach number in the observer direction is denoted by $M_{r}$, and the Lighthill stress tensor by $\boldsymbol{T}$. The force acting on the surface, in the second term, constitutes of the normal component of the pressure $p$ and viscous shear stress $\boldsymbol{\tau}$. In the last term, $\rho_{\infty}$ and $v_{n}$ denote the density at infinity and normal velocity of the solid surface $\partial V_{H}$, respectively.

Quadrupole noise constitutes of volume sources and generally becomes important at higher Mach numbers 
where, e.g., blade shocks occur. For helical Mach numbers $M_{H}$ up to 0.6, the sound radiation is dominated by loading noise, for high subsonic Mach numbers by thickness noise. The loading noise term is highly directional, with a pronounced maximum at a polar angle $\phi$ slightly larger than 90 degrees to the propeller axis (downstream) and a smaller peak at polar angle slightly smaller than 90 degrees. Here, the polar angle equals zero for the upstream direction, 90 degrees for the propeller plane, and 180 degrees for the downstream direction. Thickness noise dominates for high subsonic Mach numbers, and has a strong directivity, i.e., mainly radiating in the propeller plane $\left(\phi \approx 90^{\circ}\right)$. On the rotor axes, no sound is radiated for an isolated propeller, as $M_{H r}$ (the helical Mach number projected in the observer direction) becomes zero, and all surface integral terms are zero in Eq. (1).

Subsonic Propellers with $B$ number of blades generate so-called rotating tones, characterized by discrete tonal contributions in a narrowband spectrum. These discrete tonal contributions occur at frequencies called blade passing frequencies (BPF), i.e.,

$$
\mathrm{BPF}_{n}=\frac{n B N}{60}, \quad \text { for } \quad n=1,2,3, \ldots
$$

For $n=1$, Eq. (1) denotes the fundamental frequency, and for $n>1$ the $n$-th Harmonic frequency. Gutin, ${ }^{1}$ already in 1936, predicted the propeller harmonics. Hanson ${ }^{5}$ extended this by including flight effects. For Mach numbers below 0.8, a linear decrease of the amplitude is observed for increasing harmonics. This decrease is stronger for lower Mach numbers $M_{H}$ (see, e.g., ${ }^{3}$ ).

\section{B. The installed propeller sound field}

Propeller sound alters significantly as a result of installation, due to angle changes or non-uniformity of the inflow (e.g., pylon wake at a propeller in pusher configuration). When the non-uniformity is stationary, no new frequencies are introduced. However, the amplitude and directivity strongly alter. Especially installed propellers radiate more omni-directional. If the inflow is unsteady, as is the case for Contra-Rotating Open Rotors, new frequency components appear in the spectrum (see, e.g., ${ }^{6-8}$ ).

\section{Experiments related to (installed) propeller sound}

Although theoretical research on propellers commenced already long ago (see, e.g., Gutin ${ }^{1}$ ), experimental research on propeller aeroacoustics is already more scarce. A short overview of some literature is given for isolated propellers, propeller mounted on a wing to mounted on a full aircraft.

One of the first experimental aeroacoustic propeller studies was performed by Succi et al., ${ }^{9}$ who compared a prediction model with aeroacoustic experiments concerning isolated propellers. Three different propeller designs were tested, i.e., with different blade loadings, as well as three different nacelle geometries (the latter was said to be of minor significance). Accurate results were shown for the comparison between the acoustic model and the experiments for the isolated propeller (for varying operating conditions, tip speeds, and propeller-nacelle combinations). Similar results were found by Zandbergen et al. ${ }^{10}$ for an isolated propeller at zero angle of attack.

Block ${ }^{11}$ reported on an experimental investigation of installation effect on propellers. She compared an isolated single propeller and two contra-rotating propellers, mounted in the tractor configuration on a sting, as well as a semi-installed single propeller in tractor and pusher configuration (i.e., pylon in front of the propeller or behind). Increased noise arises from an increase in unsteady loading, which mainly radiates in axial direction. Shivashankara et al. ${ }^{12}$ investigated a rear-fuselage mounted CROR (in pusher configuration), more specifically the General Electric UDF engine equipped with contra-rotating propellers. The main source of noise increase due to installation here was the pylon wake interaction with the CROR. Maybe even more interesting, they investigated pylon blowing as a mean to reduce installation effects resulting from the impingement of this pylon wake on the front rotor. They showed that they could reduce the pylon wake with this blowing technique and could bring back the installed front BPF levels to that of the isolated CROR configuration.

Tanna et al. ${ }^{13}$ performed aeroacoustic experiments on the left outer wing (of a scaled model) of a Lockheed C-130 Hercules with the outboard engine and propeller mounted. In this study aerodynamic installation as well as acoustic installation are considered. They identify the propeller angle of attack and the propeller inflow distortion due to the upstream potential effect of the wing as important installation effects for propeller noise. 
Zandbergen et al. ${ }^{14}$ present aeroacoustic results of experiments on a full model (i.e., Fokker F27) in a untreated (non-anechoic) DNW wind tunnel. Effects of propeller rotational speed (both propeller rotate in clock-wise direction), wind tunnel speed, and angle of attack were studied. Although most results were as expected, they also showed the expected asymmetric sound emission of an airplane when the two propellers rotating in the same direction.

\section{Experimental setup}

\section{A. Model}

The wind tunnel model is a one-ninth scale starboard wing, it consists of a propeller mounted in front of a wing which produces a high lift due to the utilisation of a Coanda flap. The wing profile is a modified DLR F15 profile, where the flap is rotated by 65 degrees around a point located on the pressure side at $75 \%$ local chordlength $c$. At the suction side, a blowing slid is introduced that injects air tangentially to the flap surface at that location. The blowing slid height is set to 6 per mille of the profile thickness. The wing is equipped with a sweep angle of 10 degrees and a total wing span consisting of $1.6 \mathrm{~m}$. Over this complete spanwise extent, the Coanda flap is present. Although not used in the here described experiments, an optional outboard tapered extension with ailerons can be installed. For a global schematic, the reader is referred to figure 1 (a).

A nine-bladed propeller [see, e.g., figure 1(b)] is mounted in front of the above described high-lift wing.

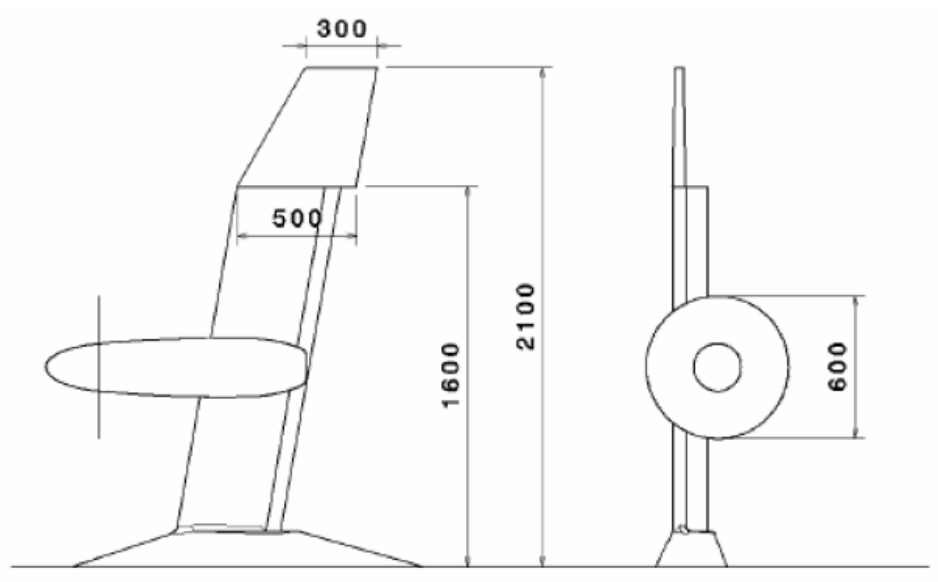

(a)

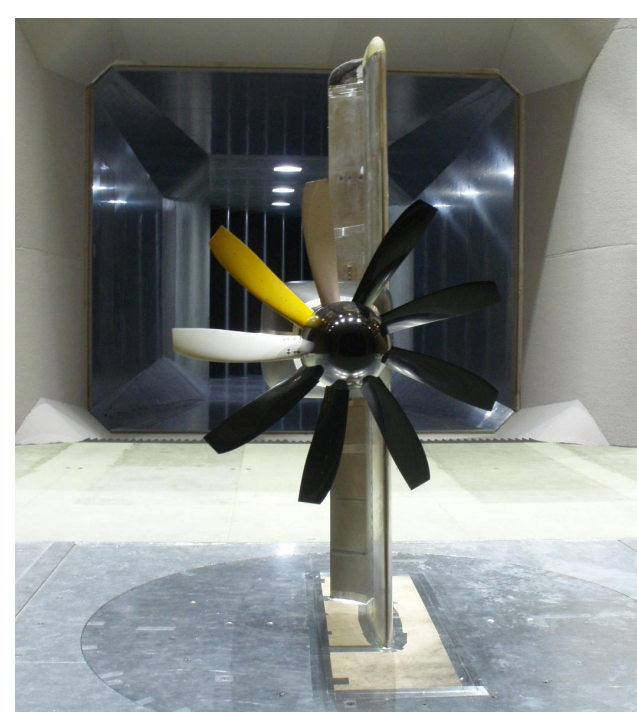

(b)

Figure 1. (a) Schematic of the BNF model, including the optional outboard extension. Note that this outboard extension is not used in the here described experiments. (b) Front view of the model in the open test section in the aeroacoustic NWB wind tunnel.

This propeller has a diameter of $0.667 \mathrm{~m}$. For the propeller design, the interested reader is referred to Lenfers. ${ }^{15}$ One of the propeller blades is instrumented with unsteady pressure transducers. The propeller is driven by an electro motor, which provides a power of $180 \mathrm{~kW}$ at a rotational speed of 7144 revolutions per minute. This was mainly determined to reach a certain target thrust during take-off.

\section{B. NWB and measurement technique}

The aeroacoustic measurements have been performed in the NWB (Niedergeschwindigkeits Windkanal Braunschweig) wind tunnel. This facility is located at DLR Braunschweig in Germany. The previously aerodynamic windtunnel NWB has been upgraded to an aeroacoustic windtunnel in 2011, while retaining its aerodynamic capabilities. This wind tunnel is a low-speed wind tunnel of the Göttinger-type, where the open test section 
lies inside an anechoic chamber (a closed test section is used for aerodynamic experiments). The nozzle size measures approximately $3 \times 3 \mathrm{~m}^{2}$. From this nozzle, a ground floor is positioned which forms a prolongation of the lower nozzle-exit plane towards the collector. This ground plane is wider then the nozzle (or collector) width, so as to minimize interaction of the shear layer emanating from this nozzle and the ground plate edge [see, e.g., figure 1(b)].

The windtunnel is powered by a $3.5 \mathrm{MW}$ fan, which is capable of providing a continuous free stream velocity

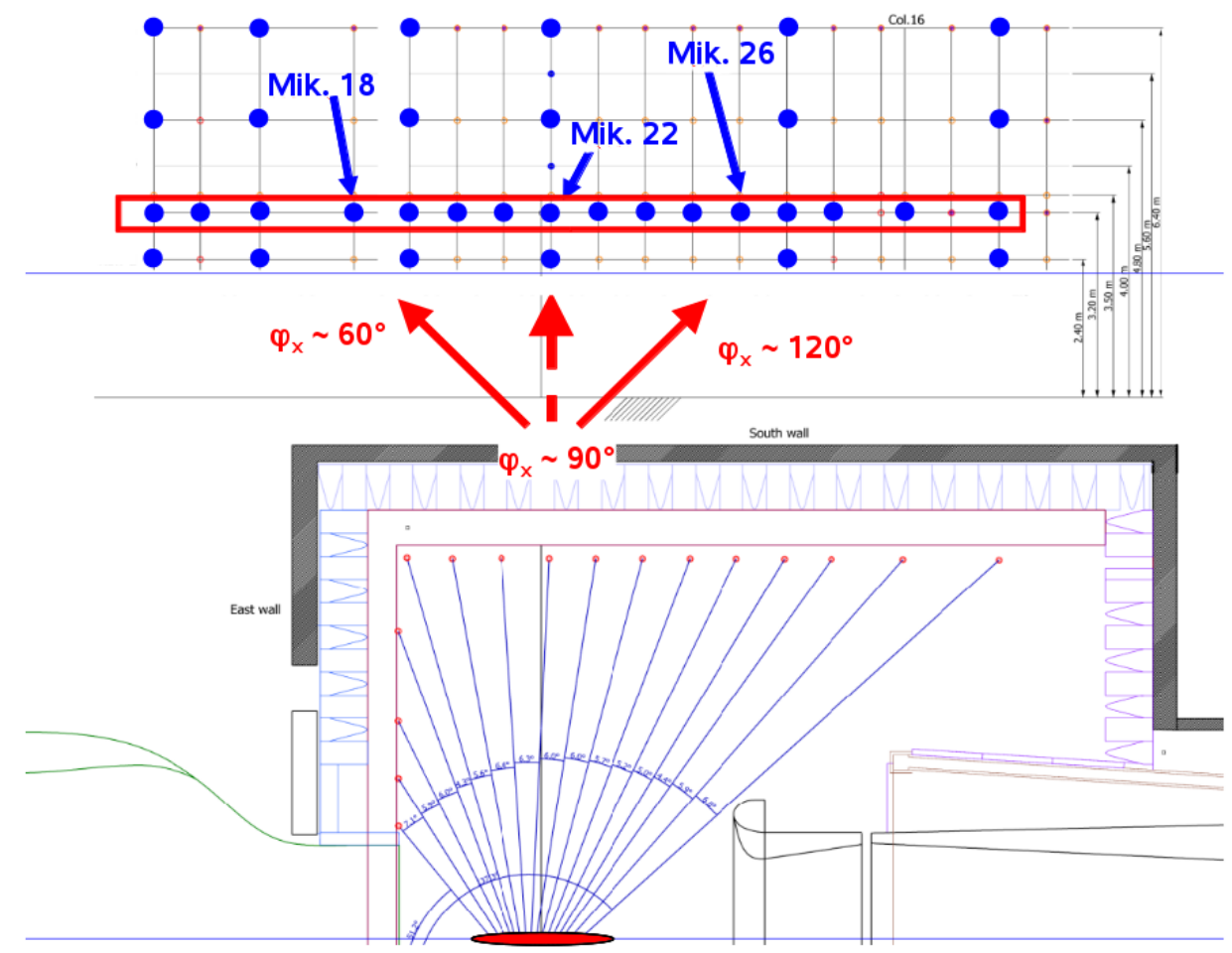

Figure 2. Plan view of the NWB open test section (lower part of figure), with the far field microphone position indicated in the top part of the figure. A total of 36 farfield microphones were used.

of $80 \mathrm{~m} / \mathrm{s}$ in the open test section. See lower part of figure 2 for a planview schematic of the open test section. The acoustic characteristics of the new NWB have been thoroughly evaluated by Pott-Pollenske et al. ${ }^{16}$

\section{Wind tunnel corrections applied to data}

Basically, two kinds of far field (FF) measurements were performed, FF microphone measurements and microphone array measurements. A total of $36 \mathrm{FF}$ microphones (4 microphone rows) we mounted on the side wall of the anechoic chamber [the wall located left of the model in figure 1(b), i.e., the downward noise radiation direction]. A schematic of the FF microphone positions is provided in the top part of figure 2. The microphone row delineated by the red rectangle indicates the microphones used for the polar directivity measurements and span a polar angle from approximately 30 to 150 degrees. The sampling rate of these microphones was $60 \mathrm{kHz}$, so that narrow band spectra up to $30 \mathrm{kHz}$ are possible. A fast Fourier transform is applied to the time signal to obtain the sound pressure spectrum (where the frequencies are chosen such that the blade passing frequencies of the test case are met).

Besides FF microphone measurements, also the microphone array technique was applied for the purpose of localisation and assessment of the sound sources. This microphone array consists of 140 microphones, mounted in an array surface of approximately $3 \times 3 \mathrm{~m}^{2}$. The array surface has a distance of $3.4 \mathrm{~m}$ to the wind tunnel model, with the array surface parallel to the chord of the wing (outside of the flow and facing the pressure side of the wing). The microphones of the array were sampled at $60 \mathrm{kHz}$, which resulted in evaluated signals up to $25 \mathrm{kHz}$ in one-third octave bands. To perform a microphone array measurement, the array was traversed to a position so as to cover the wing including the propeller with the evaluation surface. One scan area is used that covers the complete wing and propeller, while secondary scan areas were used to assess the individual source contributions. 
Sound source maps were generated by means of the delay and sum beamforming technique in the frequency domain. The above procedure provides a feasibility to localise broadband sound sources. To study the tonal sound radiation by a propeller sound source, the following alternative processing is used. In a similar way as can be done with the Particle Image Velocimetry (PIV) technique, averaging over several measurement images (to get rid of the random part, i.e., the seeding particles) is utilized to obtain a background image containing the steady part (the reflections). ${ }^{17}$ Here, we average over several realisations to average out the random part (broadband noise sources) to obtain the periodic (or steady in a certain frame rate) part of the signal, i.e., the propeller.

On the data of the FF microphones several corrections have been applied to obtain the true source characteristics from the wind tunnel out-of-flow acquired acoustic data, in the following order:

1. Correction for shear-layer refraction and wave convection,

2. Atmospheric absorption (in narrow bands),

3. Correction for convective amplification,

4. Data normalisation to 1 meter distance

The source location, needed for the wind tunnel shear layer correction, was chosen to be the propeller rotation center point. As we are primarily interested in the tonal sound radiation of the propeller, the results are mainly based on narrowband spectra. Correction for the microphone directivity was not performed as such directivity correction is not available in narrow band. Furthermore, background noise subtraction (in narrow bands) was not performed as this background noise was significantly smaller than the measured signal and therefore results in no qualitative difference in the results. Also, no correction for source power to reference atmosphere was applied as this generally leads to minor corrections below $1 \mathrm{~dB}$. For more general information regarding the applied correction methods, the interested reader is referred to Refs. ${ }^{18-20}$

\section{Testmatrix}

Several experimental configurations were measured, where the angle of attack $\alpha$, wind tunnel velocity $V_{\infty}$, blade pitch angle $\beta$, and rotational speed of the rotor $N_{P}$ were varied. Three angle of attacks $(\alpha=\{-10,-5,0\})$, three wind tunnel velocities $\left(V_{\infty}=\{30,40,51\} \mathrm{m} / \mathrm{s}\right)$, five blade pitch angles $(\beta=$ $\{22,25,28,31,34\})$, and three rotational speeds $\left(N_{P}=\{3450,5105,7144\} \mathrm{rpm}\right)$ were measured in different combinations. However, certain $\beta$ and $N_{P}$ parameter combinations were prohibited due to maximum power by the engine (high-thrust limitation) or that the engine could not handle the so-called "windmilling" situation (low-thrust limitation). In this proceeding, we will mainly focus on the different cases for angle of

\begin{tabular}{ccccccc}
\hline \hline & & \multicolumn{5}{c}{$\beta[-]$} \\
\cline { 3 - 6 }$N_{P}[\mathrm{rpm}]$ & & $22^{\circ}$ & $25^{\circ}$ & $28^{\circ}$ & $31^{\circ}$ & $34^{\circ}$ \\
\cline { 3 - 7 } 3450 & & $\boldsymbol{x}$ & $\boldsymbol{x}$ & $\mathrm{C} 1$ & $\mathrm{C} 2$ & $\mathrm{C} 3$ \\
5105 & & $\mathrm{C} 4$ & $\mathrm{C} 5$ & $\mathrm{C} 6$ & $\mathrm{C} 7$ & $\mathrm{C} 8$ \\
7144 & $\boldsymbol{x}$ & $\mathrm{C} 9$ & $\mathrm{C} 10$ & $\boldsymbol{x}$ & $\boldsymbol{x}$ \\
\hline \hline
\end{tabular}

Table 1. Performed experiments for the case of wind tunnel velocity $V_{\infty}=51 \mathrm{~m} / \mathrm{s}$, as function of blade pitch angle $\beta$ and propeller rotational speed $N_{P}$. Crosses mean that the specific parameter combination was not possible (caused by engine limitations). C1 to $\mathrm{C10}$ are the cases referred to in the results Section.

attack of $\alpha=-5^{\circ}$. The testmatrix for this angle of attack is given in table 1. For all the measurements, FF microphone measurements were performed as well as with the microphone array. Also, for C10 the other two wind tunnel velocities will be presented. In the results section, reference will be made to the blade passing frequencies which are listed in table 2. These BPFs are computed with Eq. (2).

Before the above measurements were performed, a sensible aerodynamic operating condition was determined. To determine this aerodynamic operating condition, use was made of preliminary results of the aerodynamic measurement campaign which was performed in the closed test section. The mass flow rate of 


\begin{tabular}{cccccc}
\hline \hline & \multicolumn{5}{c}{$\mathrm{BPF}_{n}[\mathrm{~Hz}]$} \\
\cline { 2 - 6 }$N_{P}[\mathrm{rpm}]$ & $n=1$ & 2 & 3 & 4 & 5 \\
\hline 3450 & 517.5 & 1035 & 1552.5 & 2070 & 2587.5 \\
5105 & 765.75 & 1531.5 & 2297.25 & 3063 & 3828.75 \\
7144 & 1071.6 & 2143.2 & 3214.8 & 4286.4 & 5358 \\
\hline \hline
\end{tabular}

Table 2. Fundamental Blade Passing Frequencies (BPF) and higher harmonics for the 3 considered rotational speeds $N_{P}$ of the propeller $\left(N_{P}=3450,5105,7144 \mathbf{r p m}\right)$. BPFs are listed up to $n=5$.

the Coanda jet was determined experimentally. For this purpose, flow tufts were mounted on the Coanda flap (in streamwise, as well as in spanwise direction).

\section{Results}

Aeroacoustic results are presented in this Section, however, first the operating condition is checked that no massive flow detachment occurs at the Coanda flap and that the wing is still in the linear regime of the lift curve. In the second subsection, spectral results are shown near the propeller plane as well as the polar directivities of individual BPFs. Hereafter, results are presented regarding source localisation.

\section{A. Aerodynamic operating condition}

The wing was equipped with four rows of static surface-pressure taps, so as to measure the $c_{p}$-distribution of the wing at four different spanwise positions. These are located at a distance of $300 \mathrm{~mm}$ (indicated by DV100), $578 \mathrm{~mm}$ (DV200), $1045 \mathrm{~mm}$ (DV300), and $1323 \mathrm{~mm}$ (DV400) from the wing root. Furthermore, a lift polar was measured to assure that the operating condition was still in the linear regime.

In figure $3(\mathrm{a})$ the lift polar is given for $V_{\infty}=51 \mathrm{~m} / \mathrm{s}, \beta=28^{\circ}$, and $N_{P}=71441 / \mathrm{min}$. Four different span-

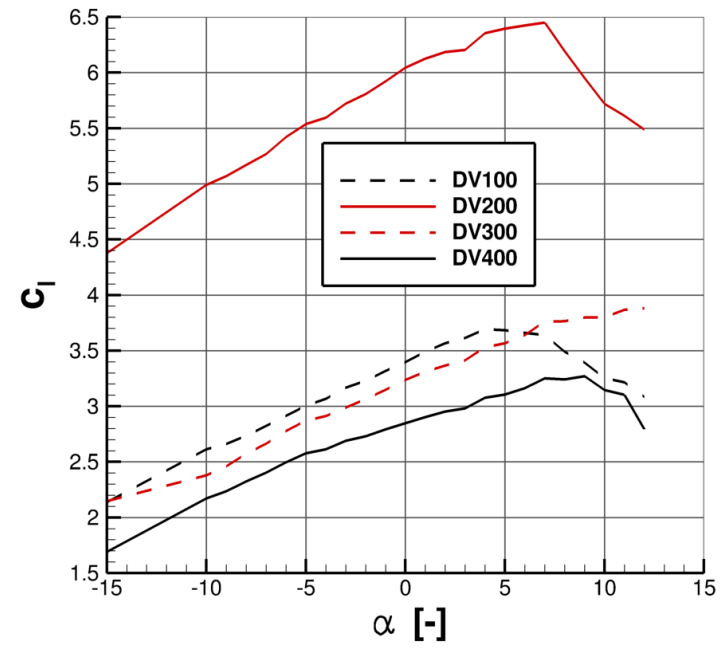

(a)

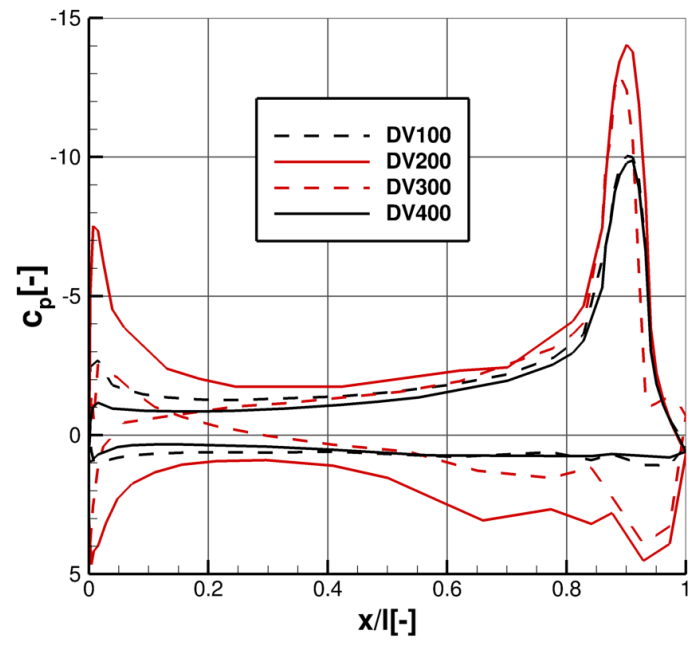

(b)

Figure 3. (a) Lift coefficient polar for case $V_{\infty}=51 \mathrm{~m} / \mathrm{s}, \beta=28^{\circ}, N_{P}=7144$ 1/min for four different spanwise positions (DV100, DV200, DV300, and DV400). (b) Pressure coefficient $c_{p}$ distribution over chord ( $\left.x / l\right)$ for four spanwise positions while keeping angle of attack $\alpha$ constant at $-5^{\circ}$.

wise locations have been evaluated, where DV100 lies inboard, DV200 inboard from the nacelle but inside the propeller slipstream, DV300 starboard side of propeller inside its slipstream, and DV400 starboard from 
propeller, outside of slipstream. Noticeable are the high $c_{l}$-values due to the Coanda flap. Especially DV200, located at the inboard side of propeller, displays a high offset from the other three curves, resulting from the combined effect of the higher velocities in the propeller slipstream and the higher effective $\alpha$ resulting from the propeller swirl (propeller rotation direction is inboard-up). For DV300 (outboard side, but still inside slipstream), the combined effect of the higher velocities but lower effective $\alpha$ lead to similar $c_{l}$-values, however, the lower effective $\alpha$ yields to flow detachment at a higher angle of attack then for the other spanwise locations. Most important, the three geometrical angle of attack values of $-10,-5,0$ lie in the linear regime of the lift polar.

For $\alpha=-5$, the pressure distribution is presented in figure 3(b), i.e., case C9 in table 1. For the most inner and outer spanwise locations (i.e., DV100 and DV400 indicated by the black dashed and solid line, respectively) a strong suction peak is seen at the suction side of the flap due to the Coanda jet and the curvature of the profile. Also, a suction peak is seen at the leading edge of DV100. For the two spanwise positions inside the propeller slipstream (DV200 and DV300) the suction peaks at the flap increases significantly due to combined effect of local $\alpha$ increase and increased velocity by the propeller stream. At the pressure side of the flap, this effect of higher velocities in the propeller wake is noticeable. At the leading edge, for DV200 a strong suction peak is seen (local $\alpha$ effect due to inboard-up rotation), and for DV300 it is seen that the stagnation point is located at the suction side due to this same effective angle of attack. For DV300, it can be noticed that just before the trailing edge flow separation occurs. Note that DV300 is located at the outboard-downward propeller blade side.

In figure 4 the spanwise $c_{p}$-distribution is presented for the case for case $V_{\infty}=51 \mathrm{~m} / \mathrm{s}, \beta=28^{\circ}$,

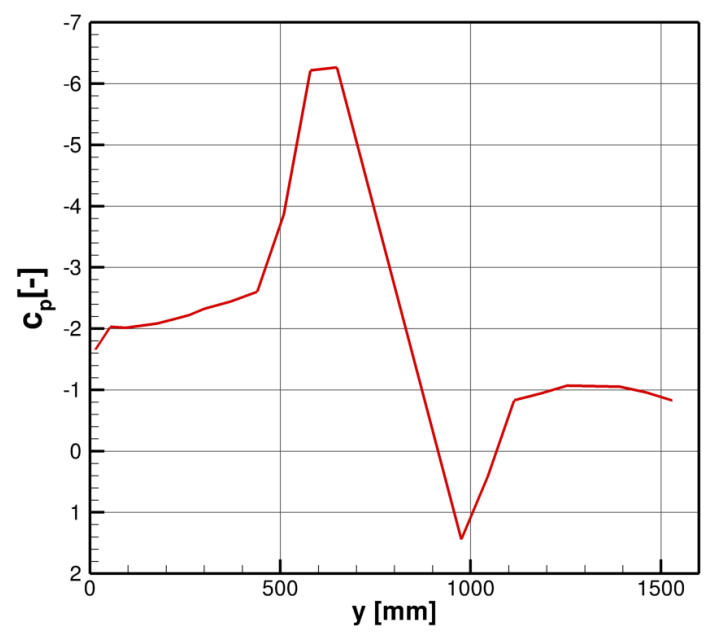

Figure 4. Pressure coefficient $\left(c_{p}\right)$ distribution in spanwise direction $(y)$ for case $V_{\infty}=51 \mathrm{~m} / \mathbf{s}, \beta=28^{\circ}$, $N_{P}=7144$ 1/min.

$N_{P}=71441 / \mathrm{min}$. This distribution is mainly influenced by the simultaneous effects of the increased axial velocity (symmetrical effect) and the swirl in the propeller slipstream (anti-symmetric effect). Here, the effect of the swirling propeller slipstream is seen with the inboard-up rotation direction (together with the increased axial velocity in the slipstream) leading to considerable higher inboard $c_{p}$-values.

Note that the angle of attack range of the linear regime ranges approximately from -10 to 0 degrees [see figure 3(a)]. This would suggest a negative angle of attack during landing, which is clearly not practical. However, for the current generic aeroacoustic study we are interested in a properly functioning Coanda flap. This undesirable (negative) angle of attack during approach can in practice be remedied by equipping the wing with a droop nose. 


\section{B. Farfield noise spectrum around propeller plane}

The influence of variation of propeller rotational speed is presented in figure $5(\mathrm{a})$, for the case $V_{\infty}=51 \mathrm{~m} / \mathrm{s}$, $\alpha=-5$, and $\beta=28^{\circ}$. The combination of this blade pitch angle with the different shaft rotational speeds $N_{P}=\{7144,5105,3450\} \mathrm{rpm}$ yields approximately $100 \%, 50 \%$ and $0 \%$ thrust, respectively. For the lowest

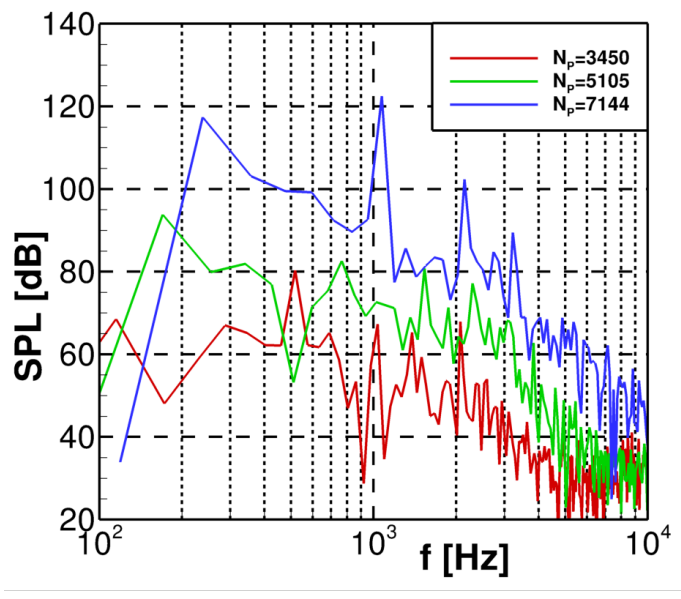

(a)

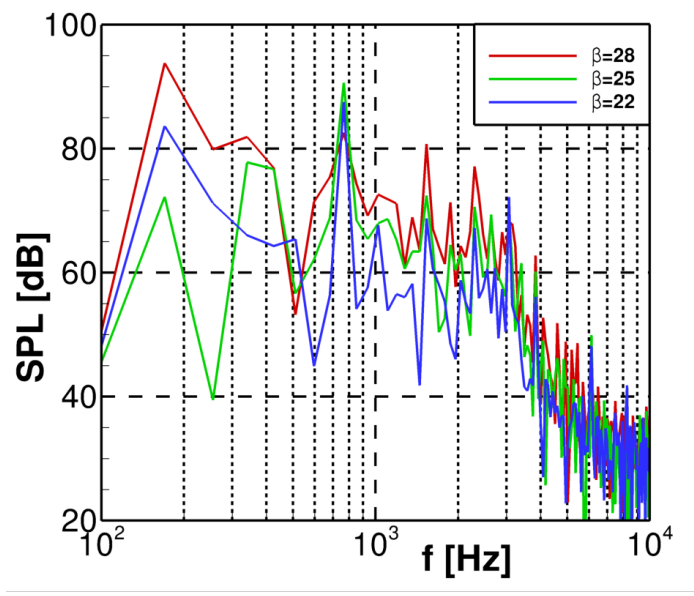

(b)

Figure 5. (a) Farfield sound spectra for varying rotor revolution speed $N_{P}$ of case $V_{\infty}=51 \mathbf{m} / \mathbf{s}, \alpha=-5$, and $\beta=28^{\circ}$. (b) Farfield sound spectra for different blade pitch angles $\beta$ of case $V_{\infty}=51 \mathrm{~m} / \mathbf{s}, \alpha=-5$, and $N_{P}=51051 /$ min.

rotational speed of $N_{P}=34501 / \mathrm{min}$, the first blade passing frequency $\mathrm{BPF}_{1}$ can be seen, $\mathrm{BPF}_{4}$ to a lesser extent. The second BPF is barely noticeable in the spectrum at $1035 \mathrm{~Hz}$. For the next higher propeller revolution speed, i.e., $N_{P}=51051 / \mathrm{min}$, a broadband noise level increase of $10 \mathrm{~dB}$ becomes evident from the spectrum. All blade passing frequencies (see table 2) are identifiable, although $\mathrm{BPF}_{4}$ and $\mathrm{BPF}_{5}$ less pronounced. For the highest $N_{P}$, an increase of approximately $10 \mathrm{~dB}$ is again seen for the broadband noise level as well as an increase of the tonal peaks. Blade passing frequency $\mathrm{BPF}_{1}$ to $\mathrm{BPF}_{3}$ are distinguishable.

In figure 5(b) the influence of a varying blade pitch angle $\beta$ is displayed, while keeping other parameter constant (i.e., $V_{\infty}=51 \mathrm{~m} / \mathrm{s}, \alpha=-5$, and $N_{P}=51051 / \mathrm{min}$ ). Note that by changing the blade pitch angle $\beta$, only the loading term is changes and the thickness noise remains constant [see, e.g., Eq. (1)]. Comparison between spectra for $\beta=28$ and 25 degrees yields a small broadband noise decrease of approximately $1 \mathrm{~dB}$ as well as a (larger) tonal noise amplitude decrease. However, for $\mathrm{BPF}_{1}(765.75 \mathrm{~Hz})$ a noticeable reduction of $8 \mathrm{~dB}$ is observed. For $\beta=22$ a similar reduction of the broadband noise level is seen compared to 25 degrees pitch angle, and the peak level of $\mathrm{BPF}_{1}$ increases. For all three blade pitch angles, the fundamental $\mathrm{BPF}$ is the dominant tone. Also, tonal peaks are observed at frequencies below $\mathrm{BPF}_{1}$ for the three cases, i.e., proportional to the shaft rotational speed. The most obvious reasons for this are a possible vibration of the propeller shaft, or a cyclic loading of the propeller due to small difference in the blade pitch settings of the individual blades.

In a similar way as in the previous figure, the spectral dependence on wind tunnel velocity $V_{\infty}$ is presented in figure 6(a), and in 6(b) for variation with angle of attack $\alpha$. The tonal levels consistently decrease (up to $\mathrm{BPF}_{3}$ ) with approximately $2 \mathrm{~dB}$ with increasing $V_{\infty}$. This could be explained by a decrease in thrust with increasing windtunnel velocity (as the velocity increase before and after propeller decreases with increasing $V_{\infty}$ ), and hence a lower magnitude of the tonal sound. For the broadband noise level it is difficult to observe a clear trend with increasing $V_{\infty}$.

A decay of the tonal amplitudes with increasing harmonics is evident from this figure. This decay can also be estimated with the simplified formula (see, e.g., ${ }^{3}$ )

$$
\mathrm{SPL}_{n} \sim 20 \log \left[n B M_{\Omega} J_{n B}\left(0.9 n B M_{\Omega}\right)\right] .
$$

This equation described the sound pressure level of point sources rotating at a radius of $90 \%$ of the propeller blade radius. No convective effects are taken into account (e.g., $M_{\Omega}$ ), nor is there any form of installation. 


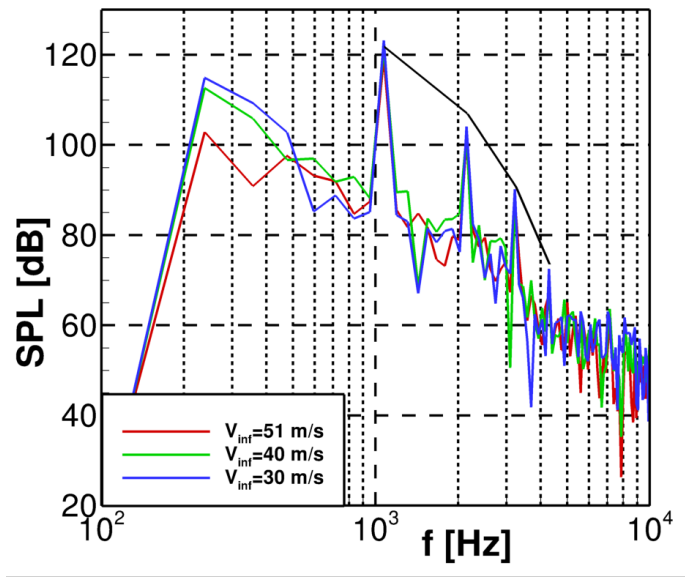

(a)

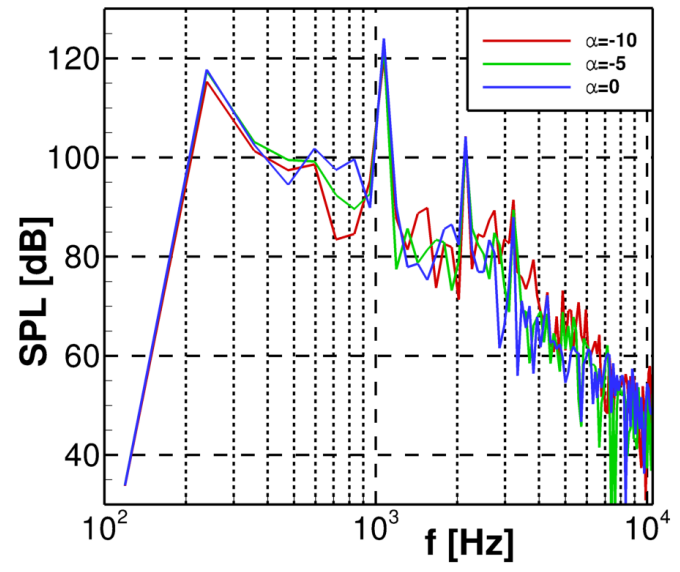

(b)

Figure 6. (a) Farfield sound spectra for case $N_{P}=71441 / \mathrm{min}, \alpha=-5$, and $\beta=25^{\circ}$, while varying the wind tunnel speeds $V_{\infty}$. The black solid-line represents the expected theoretical scaling of the blade passing frequency decay, as given by Eq. (3). (b) Farfield sound spectra for different angles of attack $\alpha$ of case $V_{\infty}=51 \mathrm{~m} / \mathrm{s}$, $\beta=28$, and $N_{P}=7144 \mathbf{1} / \mathrm{min}$.

The number of blades is denoted by $B$ and $n$ represents the $n$-th harmonic. A Bessel function of the first kind and order $n B$ is implied by $J_{n B}$. The close agreement of the experimental data and the theoretical scaling, as illustrated in figure 6(a), suggests that the installation effects of the wing and nacelle on the thickness noise $\left(M_{H}>0.6\right)$ are minor and confirms that indeed the propeller is primarily responsible for the tonal content. Equation (3) predicts a steeper decay with decreasing $M_{\Omega}$ (or $N_{P}$ ), which is clearly not the case when considering the flatter spectra in figure 5(a) for the lower shaft rotational speeds $N_{P}$.

In figure $6(\mathrm{~b})$, only a small dependence of the spectra is displayed on the angle of attack suggesting that the propeller inflow hardly changes with $\alpha$.

\section{Influence of polar radiation direction}

In figure 7 , spectra are presented for variations of blade pitch angle $\beta$ for polar angles $\phi$ of (a) $60^{\circ}$, (b) $90^{\circ}$, and (c) $120^{\circ}$. Note that figure 7 (b) is the same case as the one displayed in figure $5(\mathrm{~b})$. In downstream

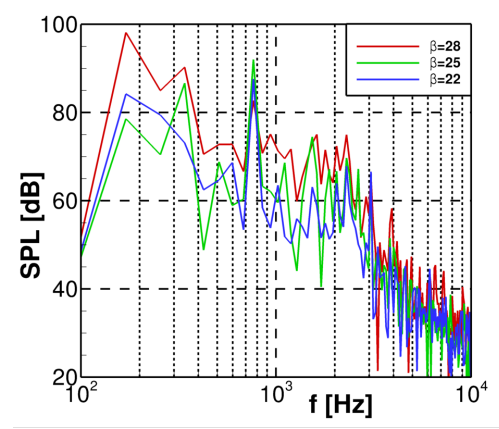

(a) upstream at $\phi=60^{\circ}$

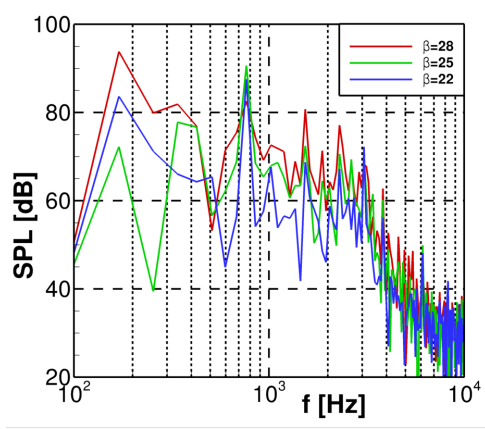

(b) propeller plane, $\phi=90^{\circ}$

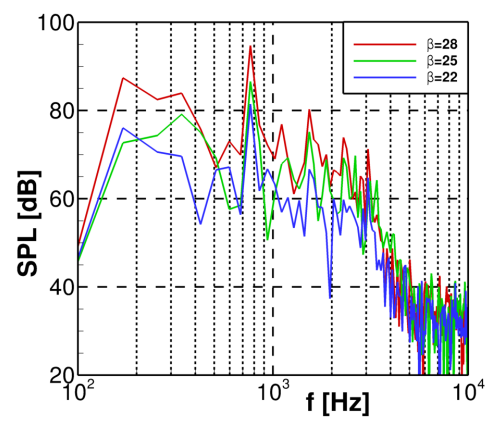

(c) downstream at $\phi=120^{\circ}$

Figure 7. Spectra of different blade pitch angles $\beta$ (for case $V_{\infty}=51 \mathrm{~m} / \mathrm{s}, \alpha=-5$, and $N_{P}=51051 / \mathrm{min}$ ) for polar angles $\phi$.

direction, the SPL amplitudes of the tonal noise is consistently higher as the lower blade pitch cases (i.e., with lower thrust). Except for the first BPF, this is also consistent for the more upstream directions [see figures $5(\mathrm{~b})$ and (a)]. In the upstream direction the $\mathrm{BPF}_{1}$ of $\beta=28^{\circ}$ has lowest value. Furthermore, again 
frequencies with significant amplitude can be appreciated below the fundamental blade passing frequency.

In figure 8 the polar directivity (in streamwise direction) for the first two blade passing frequencies is depicted for the case $V_{\infty}=51 \mathrm{~m} / \mathrm{s}, \beta=28^{\circ}, N_{P}=71441 / \mathrm{min}$, and $\alpha=-5^{\circ}$. Here, a lobe is seen in the downstream direction for both blade passing frequencies. For the $\mathrm{BPF}_{1}$ also a strong upstream lobe is seen. This could be due to installation effects although Hanson showed this can result from convective effects. ${ }^{5}$

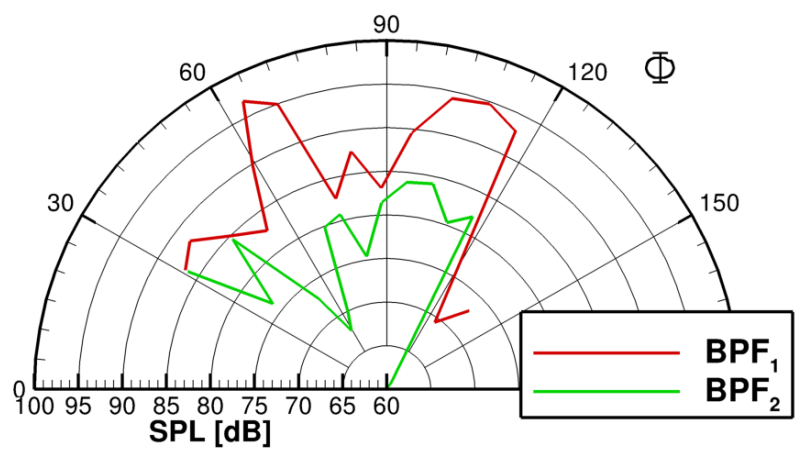

Figure 8. Polar directivity for the first two blade passing frequencies $\left(\mathbf{B P F}_{1} \text { and } \mathbf{B P F}\right)_{2}$ for case $V_{\infty}=51 \mathrm{~m} / \mathrm{s}$, $\beta=28^{\circ}, N_{P}=51051 / \mathrm{min}$, and $\alpha=-5^{\circ}$. The polar angle is denoted by $\Phi$.

\section{Array technique: source localisation and importance of broadband noise}

With the array technique, insight can be gained in the importance of different sources. In figure 9 source localisation plots are presented for the one-third octave frequency bands with middle frequency $f_{m}$ of 800 , 1600, and $2000 \mathrm{~Hz}$ (i.e., containing the first three blade passing frequencies, respectively). For the array plot

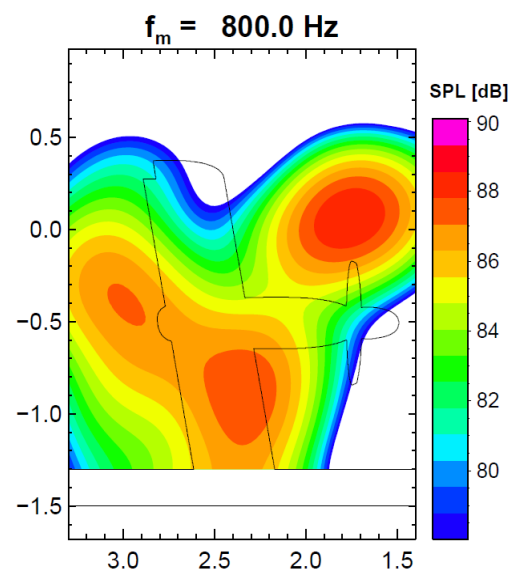

(a)

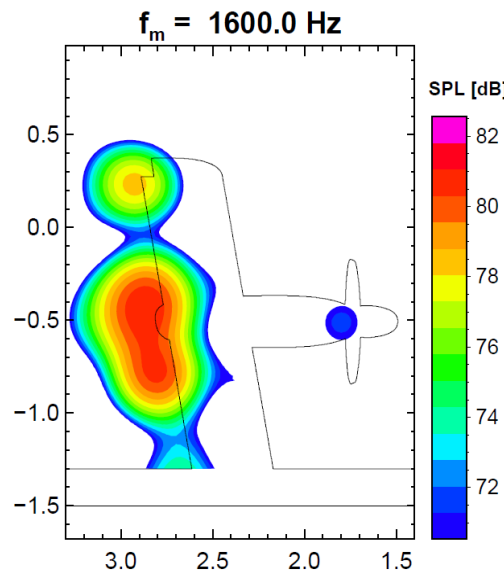

(b)

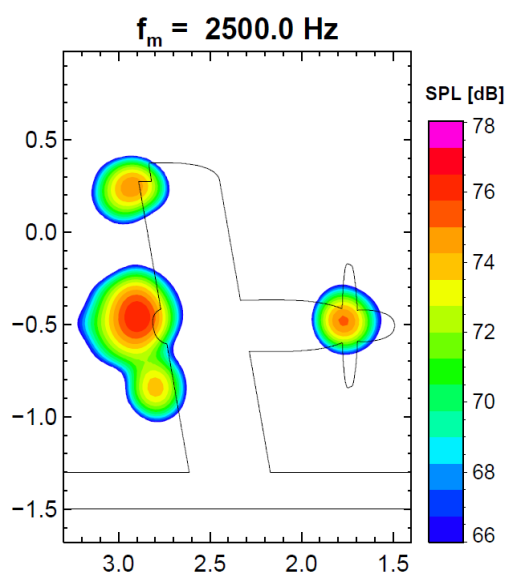

(c)

Figure 9. Source localisation plot for case $V_{\infty}=51 \mathrm{~m} / \mathbf{s}, \beta=28^{\circ}, N_{P}=5105 \mathbf{1} / \mathbf{m i n}$ for (a) $f_{m}=800 \mathrm{~Hz}$ (containing $\mathbf{B P F}_{1}$ ), (b) $f_{m}=1600 \mathbf{H z}$ (containing $\mathbf{B P F}_{2}$ ), (b) $f_{m}=2500 \mathbf{H z}$ (containing $\mathbf{B P F} \mathbf{F}_{3}$ ).

of $f_{m}=800 \mathrm{~Hz}$, it is seen that the propeller is the dominant sound source. In figures $9(\mathrm{~b})$ and (c), it is seen that there are significant sound sources located in the wake of the propeller (interaction with the Coanda flap) as well as at the flap side edge (FSE). This latter sound source mainly stems from the interaction of the strong wing-tip vortex, resulting from the large pressure difference between suction and pressure side of the wing, with the side-edge of the Coanda flap. The propeller blades are not anymore present as sound sources in this array plot. The sound source located at the propeller shaft suggests a vibration of the propeller shaft in the aforementioned frequencies below the fundamental blade passing frequency.

To further study the tonal part of the signal, an alternative post-processing has been applied. Here, the signal of one revolution is averaged over several samples, so as to average out the broadband noise part 
(random component) and retain the tonal part (periodic component). In figure 10 this is depicted for the

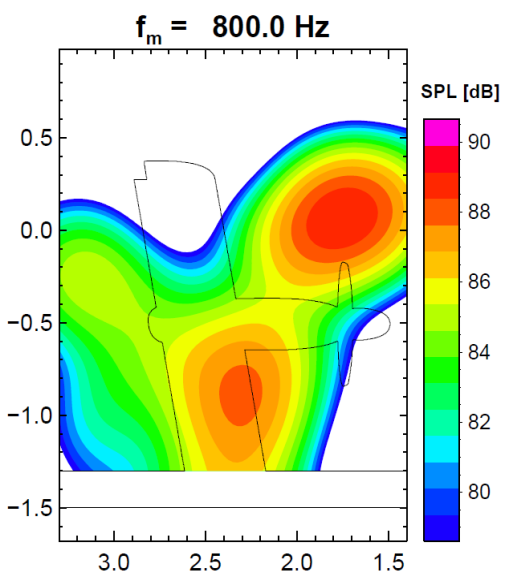

(a)

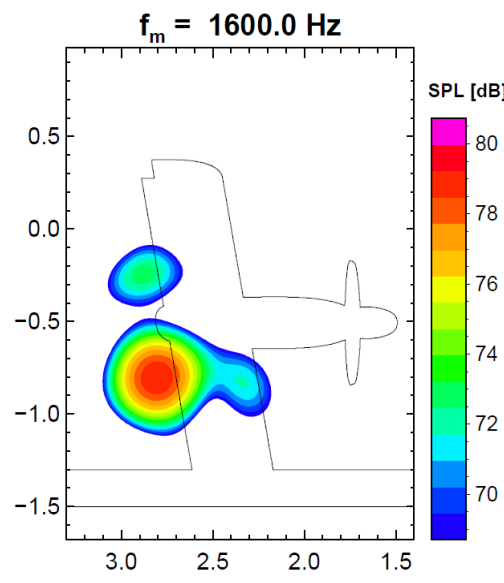

(b)

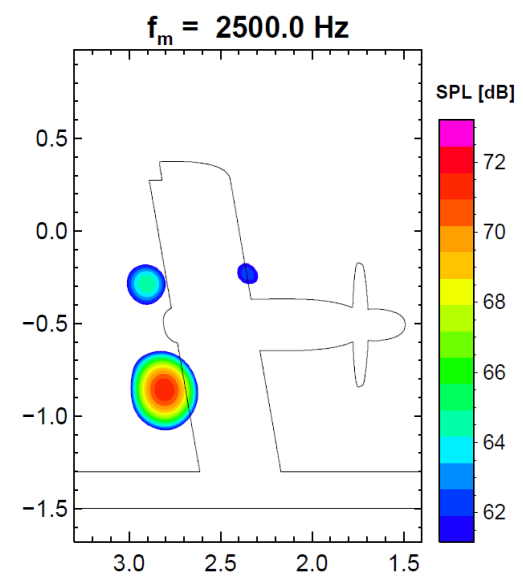

(c)

Figure 10. Source localisation plot for case $V_{\infty}=51 \mathrm{~m} / \mathbf{s}, \beta=28^{\circ}, N_{P}=5105 \mathbf{1} / \mathbf{m i n}$ for (a) $f_{m}=800 \mathrm{~Hz}$ (containing $\mathbf{B P F})_{1}$ ), (b) $f_{m}=1600 \mathbf{H z}$ (containing $\mathbf{B P F}_{2}$ ), (b) $f_{m}=2500 \mathbf{H z}$ (containing $\mathbf{B P F}$ ). The signal has been averaged over several propeller revolutions to focus on the tonal part of the signal.

same case as was already presented in figure 9. For the first subplot, figure 10(a), hardly differences are seen as the dominant sound source is the periodic propeller and this remains so after the averaging processing. For the next two displayed 1/3-octave frequency bands, a significant change is seen. The propeller shaft can not be appreciated anymore. Furthermore, the flap side edge and parts of the interaction of the propeller slip stream and flap trailing edge are now not present anymore (broadband is average out). The remaining sources are thus of a periodic nature and stem from the interaction of the propeller slipstream with (i) the Coanda flap, and (ii) to a lesser extent with the leading edge of the wing.

In figure 11 the averaged source localisation plot is displayed for the low thrust case, while in figure 12

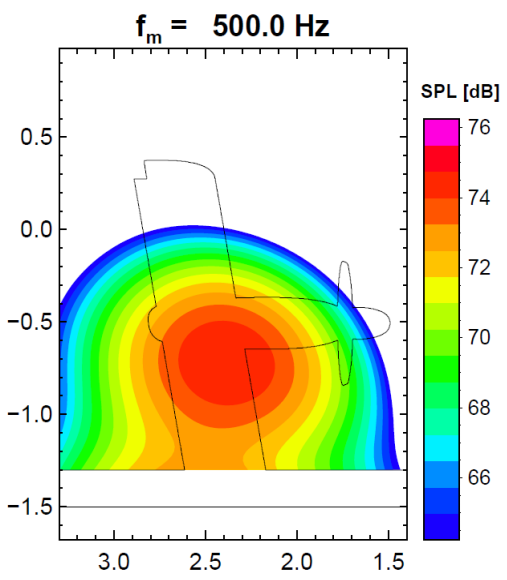

(a)

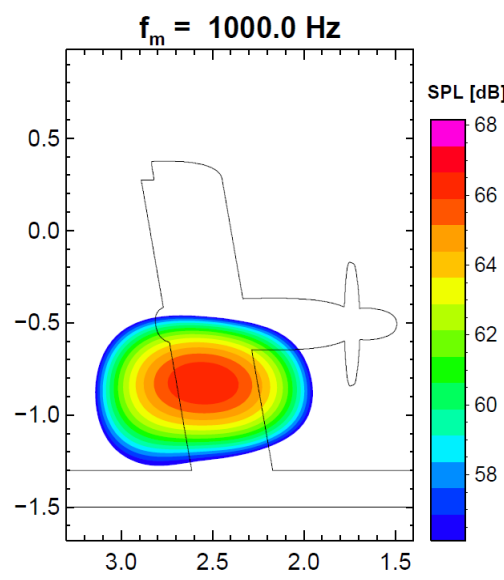

(b)

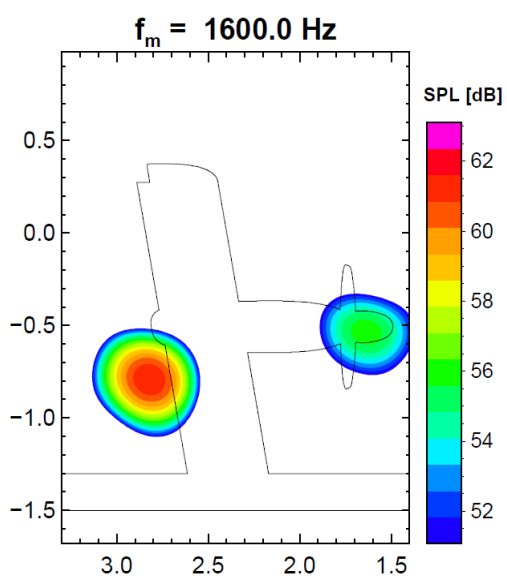

(c)

Figure 11. Source localisation plot for case $V_{\infty}=51 \mathrm{~m} / \mathbf{s}, \beta=28^{\circ}, N_{P}=34501 / \mathbf{m i n}$ for (a) $f_{m}=500 \mathrm{~Hz}$ (containing $\mathbf{B P F}_{1}$ ), (b) $f_{m}=1000 \mathbf{H z}$ (containing $\mathbf{B P F} \mathbf{F}_{2}$ ), (b) $f_{m}=1600 \mathbf{H z}$ (containing $\mathbf{B P F}$ ). The signal has been averaged over several propeller revolutions to focus on the tonal part of the signal.

this is depicted for the high thrust case (achieved by a variation of $N_{P}$ ). For the low thrust case, the propeller blades do not appear as sound sources. The propeller shaft is seen as a sound source for the one-third octave band containing $\mathrm{BPF}_{3}$ [see figure 11(c)]. For the high thrust case, see figure 12, the propeller blades can be clearly identified as the dominant sound sources for all three one-third octave bands (containing the first three BPFs).

In figure 13 the averaged source localisation plot is displayed for the medium thrust case $\left(\beta=25^{\circ}\right.$ 


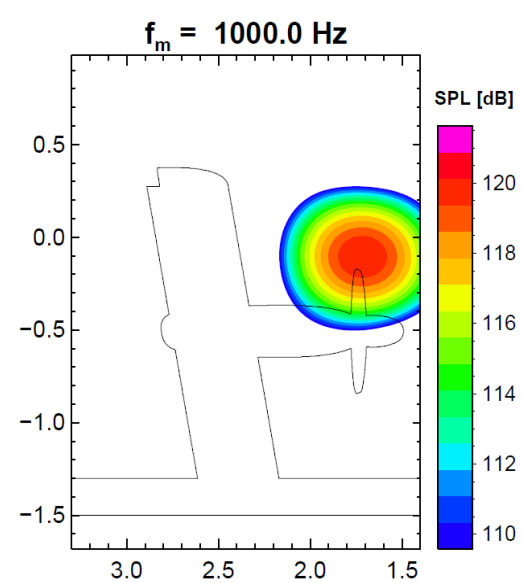

(a)

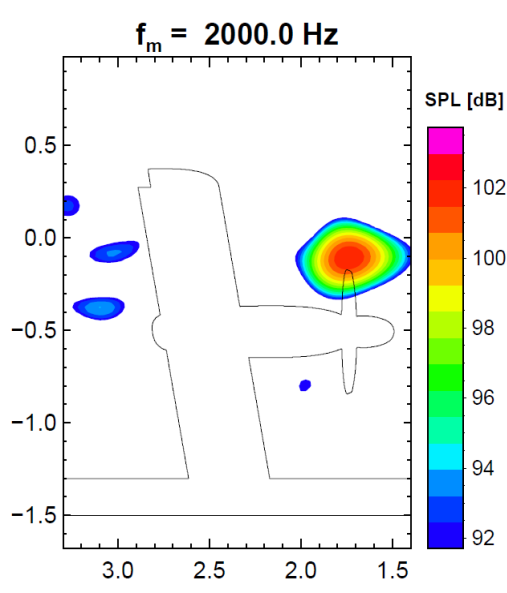

(b)

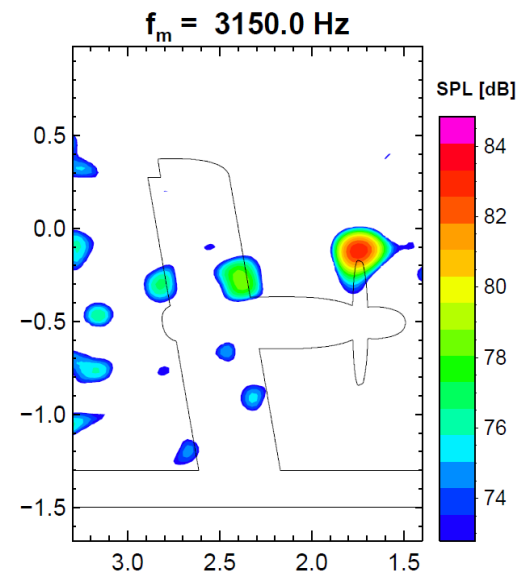

(c)

Figure 12. Source localisation plot for case $V_{\infty}=51 \mathbf{m} / \mathbf{s}, \beta=28^{\circ}, N_{P}=7144 \mathbf{1} / \mathbf{m i n}$ for (a) $f_{m}=1000 \mathbf{H z}$ (containing $\mathbf{B P F})_{1}$ ), (b) $f_{m}=2000 \mathbf{H z}$ (containing $\mathbf{B P F}_{2}$ ), (b) $f_{m}=3150 \mathbf{H z}$ (containing $\mathbf{B P F}$ ). The signal has been averaged over several propeller revolutions to focus on the periodic part of the signal.

and $N_{P}=51051 / \mathrm{min}$, with $V_{\infty}=51 \mathrm{~m} / \mathrm{s}$ and $\alpha=-5^{\circ}$ ). In the left plot, the propeller blade is seen to be the dominant sound source, where as in the middle and right figure, the propeller blade do not seem to be present as sound sources. The latter suggests that only an interaction of this propeller sound field and the

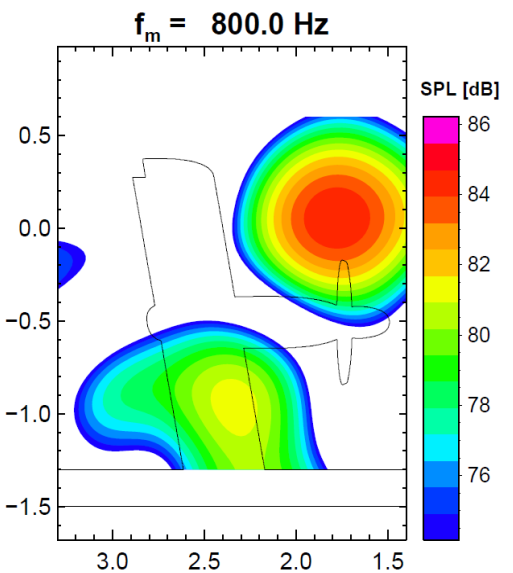

(a)

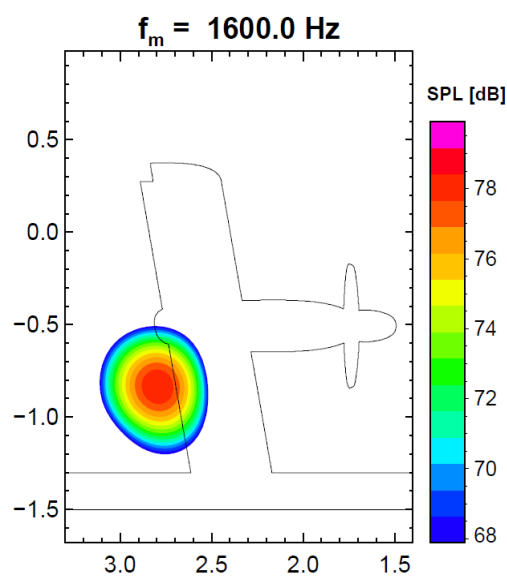

(b)

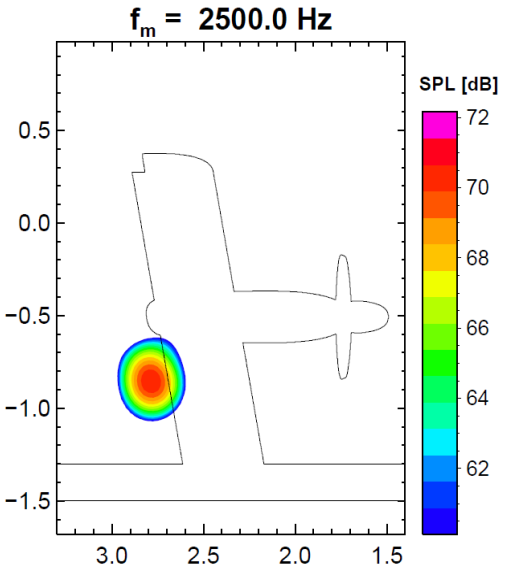

(c)

Figure 13. Source localisation plot for case $V_{\infty}=51 \mathrm{~m} / \mathbf{s}, \beta=25^{\circ}, N_{P}=5105 \mathbf{1} / \mathbf{m i n}$ for (a) $f_{m}=800 \mathrm{~Hz}$

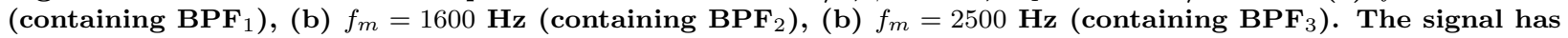
been averaged over several propeller revolutions to focus on the tonal part of the signal.

Coanda flap radiates noise.

\section{Conclusion}

Within the framework of the German collaborative research project "Bürgernahes Flugzeug" (English: Metropolitan Aircraft), aeroacoustic installation effects were investigated for a propeller mounted in front of a high-lift wing. Such a propeller mounted on a high-lift wing (employing the Coanda effect to generate a high lift) was studied in a generic setting to facilitate a substantial integration of small regional airports within the European aviation network. Aeroacoustic installation studies are important as the increased engine size often leads to a stronger geometric coupling of the propulsion system and the, in this case, wing. Although the aeroacoustic experiments are intended for validation purposes of the numerical modeling in 
the BNF project (see Ref. ${ }^{2}$ ), they are a valuable aeroacoustic dataset in itself.

We have presented the results of aeroacoustic experiments of a propeller installed in front of a high-lift wing equipped with an Coanda flap. The sound radiation of the installed propeller was studied for different propeller rotational speeds, blade pitch angles, wind tunnel velocities, and angle of attacks. For these parameter settings, substantial deviations were seen with respect to the isolated propeller case. Frequencies below the first blade passing frequency (BPF) were seen in the spectra. The origin of these frequencies are thought to be from a rotor shaft vibration or an unsteady blade loading (due to slight differences of the pitch settings between the individual propeller blades). With the aid of the microphone array technique, sources could be localised. This identified broadband sound sources, such as the flap side edge and the interaction of the propeller slip stream with the Coanda flap. By averaging over several realisations, the random part could be filtered out and the tonal propeller sound studied.

\section{Acknowledgments}

The work presented in this paper was carried out in the project "Bürgernahes Flugzeug" which was established in 2009 and is partly funded by the state of Lower Saxony (Germany). Jürgen Dierke (DLR Braunschweig) is acknowledged for useful discussions.

\section{References}

${ }^{1}$ L. Gutin, On the Sound of a Rotating Propeller, NACA TM 1195, 1948.

${ }^{2}$ J. Dierke, R.A.D. Akkermans, J.W. Delfs, and R. Ewert, Installation Effects of a Propeller Mounted on a Wing with Coanda Flap. Part II: Numerical Investigation and Experimental Validation, proceedings of the 20th AIAA/CEAS Aeroacoustics Conference, Atlanta, 2014.

${ }^{3}$ J.W. Delfs, Aeroakustik, bookchapter in "Handbuch der Luftfahrzeugtechnik" by C-C. Rossow, K. Wolf, P. Horst, Carl Hanser Verlag (2014).

${ }^{4}$ J. Ffowcs Williams and D. Hawkings, Sound Generation by Turbulence and Surfaces in Arbitrary Motion, Phil. Trans. R. Soc. Lond. Vol. 264, No. 1151, pp. 321-342, 1969.

${ }^{5}$ D.B. Hanson, Influence of Propeller Design Parameters on Far Field Harmonic Noise in Forward Flight, AIAA Journal, Vol. 18, No. 11, pp. 1313-1319, 1990.

${ }^{6}$ A. Stuermer and J. Yin, Aerodynamic and Aeroacoustic Installation Effects for Pusher-Configuration CROR Propulsion Systems, 28th AIAA Applied Aerodynamics Conference, AIAA 2010-4235.

${ }^{7}$ R.A.D. Akkermans, J.W. Delfs, M. Lummer, M. Siefert, B. Caruelle, and C. Tiedemann, Handling of Non-Periodic Contra Rotating Open Rotor Data, 18th AIAA/CEAS Aeroacoustics Conference, AIAA 2012-2262.

${ }^{8}$ R.A.D. Akkermans, J.W. Delfs, C.O. Marquez, A. Stuermer, C. Richter, C. Clemen, B. Caruelle, and M. Omais, Aeroacoustic and Aerodynamic Importance of a CROR Propulsion System with unequal Rotor Rotation Speeds, In: Notes on Numerical Fluid Mechanics and Multidisciplinary Design, New Results in Numerical and Experimental Fluid Mechanics IX, Vol. 124, 2014, pp. 593-600.

${ }^{9}$ G.P. Succi, D.H. Munro, and J.A. Zimmer, Experimental Verification of Propeller Noise Prediction, AIAA 6th Aeroacoustics Conference, AIAA 80-0994.

${ }^{10}$ T. Zandbergen, S.L. Sarin, and R.P. Donnelly, Experimental/Theoretical Investigation of the Sound Field of an Isolated Propeller, including Angle of Incidence Effects, AIAA 13th Aeroacoustics Conference, AIAA-90-3952.

${ }^{11}$ P.J.W. Block, The Effects of installation On Single- and Counter-Rotation Propeller Noise, AIAA/NASA 9th Aeroacoustics Conference, AIAA-84-2263.

${ }^{12}$ B. Shivashankara, D. Johnson, and R. Cuthbertson, Installation Effects on Counter Rotation Propeller Noise, AIAA 13th Aeroacoustics Conference, AIAA 90-4023.

${ }^{13}$ H.K. Tanna, R.H. Burrin, and H.E. Plumblee Jr., Installation Effects on Propeller Noise, AIAA 6th Aeroacoustics Conference, AIAA 80-0993.

${ }^{14}$ T. Zandbergen, S.L. Sarin, and R.P. Donnelly, Propeller Noise Measurements in DNW on the Fuselage of a Twin Engine Aircraft Model, AIAA/NASA 9th Aeroacoustics Conference, AIAA-84-2367.

${ }^{15}$ C. Lenfers, Propeller Design for a future QESTOL Aircraft in the BNF Project, 30th AIAA applied aerodynamics conference, AIAA 2012-3334.

${ }^{16}$ M. Pott-Pollenske, W. von Heesen, and A. Bergmann, Acoustic Preexamination Work and Characterisation of Low Noise Wind Tunnel $D N W / N W B, 18$ th AIAA/CEAS Aeroacoustics Conference (33rd AIAA Aeroacoustics Conference), AIAA $2012-2175$

${ }^{17}$ M. Raffel, C.E. Willert, J. Kompenhans, Particle Image Velocimetry: a Practical Guide, Springer, Berlin Heidelberg New-York, 1998.

${ }^{18}$ R.K. Amiet, Correction of Open Jet Wind Tunnel Measurements for Shear Layer Refraction, AIAA paper 75-532

${ }^{19}$ G.J.J. Ruijgrok, Elements of Aviation Acoustics, Delft University Press, Delft, 1993

${ }^{20}$ M. Pott-Pollenske, J.W. Delfs, J. Reichenberger, A Testbed for large scale and high Reynolds number Airframe Noise Research, 19th AIAA/CEAS Aeroacoustics Conference, AIAA 2013-2260. 